\title{
PEMBELAJARAN MENULIS TEKS ANEKDOT MELALUI METODE NLP (PEMOGRAMAN NEUROLINGUISTIK) DENGAN TEKNIK VAKOT (VISUAL, AUDIO, KINESTETIK, OLFAKTORI, DAN RASA) PADA PESERTA DIDIK SMA NEGERI 6 BANDUNG
}

\author{
Julianto, M.Pd \\ STKIP Subang \\ zoelliantoe@ymail.com
}

\begin{abstract}
Writing text anecdote included the type of narrative essay, but not many people who knew anecdote well. It can be said in the essay writing narrative with anecdotes design is very less or rarely. In curriculum 2013 anecdotal text appears on the class X SMA / SMK / MA in Indonesian lessons. Anecdotal text appear based on external challenges of negative phenomena were made public. Negative phenomena can lead to a society that is filled with chaos and increase the index of stress. An anecdote is a kind of short stories, both fiction and nonfiction stories that tell of personal experiences and others that contain a satirical or humorous criticism, and contain a sense of concern for the crisis phenomena in the society to change a behavior. NLP is a strategy to grow social interaction and alignment of communication between teachers and learners in achieving self-confidence, understanding, and competence, and the capital NLP is important to achieve success in learning to write text anecdotes. The success of an NLP method in teaching writing text anecdote, certainly not out of extracting a rewarding and exciting experience of what is seen, heard, felt, kissed, and tasted. Thus, this method has a close relationship with VAKOT. This study is using experimental method. This type design is the development of true-experiment. This design has a control class. This study tested the $X$-class population in SMAN 6 Bandung with samples of X-IPA 3 as the control class and class $X-5$ as an experimental class. Experimental class was treated by using NLP methods with VAKOT technique. Based on the study results, the authors get the test treatment effect with the value 0.2414 which is included in the criteria of the medium treatment effect. So, the treatment method of learning NLP with VAKOTtechniques can affect anecdotes text with medium category.
\end{abstract}

Keywords : Learn writing anecdotal text, NLP methods with VAKOT techniques, experimental methods, and the results of study.

\section{ABSTRAK}

Menulis teks anekdot termasuk ke dalam jenis karangan narasi, tetapi belum banyak orang yang mengenalnya dengan baik. Dapat dikatakan dalam menulis 
karangan narasi dengan desain anekdot ini sangatlah kurang atau jarang.Pada kurikulum 2013 teks anekdot muncul pada kelas X SMA/SMK/MA dalam pelajaran bahasa Indonesia. Munculnya teks anekdot didasari oleh tantangan eksternal tentang fenomena-fenomena negatif yang dilakukan masyarakat. Fenomena negatif tersebut dapat mengakibatkan kehidupan masyarakat yang penuh dengan kesemrawutan dan meningkatnya indeks stres semakin tinggi. Anekdot merupakan sejenis cerita pendek, baik itu cerita nonfiksi maupun fiksi yang menceritakan tentang pengalaman pribadi maupun orang lain yang berisi sindiran atau kritikan yang bersifat humor, serta mengandung rasa kepedulian terhadap sebuah krisis fenomena di masyarakat untuk mengubah sebuah perilaku. NLP merupakan strategi untuk menumbuhkan hubungan interaksi sosial dan keselarasan komunikasi antara pengajar dan peserta didik dalam mencapai rasa percaya diri, pemahaman, dan kompetensi, maka NLP modal penting untuk mencapai keberhasilan dalam pembelajaran menulis teks anekdot. Keberhasilan sebuah metode NLP dalam pembelajaran menulis teks anekdot, tentunya tidak lepas dari penggalian sebuah pengalaman yang bermanfaat dan menarik dari apa yang dilihat, didengar, dirasa, dicium, dan dikecap. Jadi, metode NLP mempunyai hubungan yang erat dengan teknik VAKOT. Metode penelitian yang digunakan adalah eksperimen.Bentuk desain ini merupakan pengembangan dari trueexperiment. Desain ini mempunyai kelas kontrol. Penelitian ini diujicobakan terhadap populasi kelas $X$ di SMA Negeri 6 Bandung dengan sampel kelas X-IPA 3 sebagai kelas kontrol dan kelas X IPA-5 sebagai kelas eksperimen. Kelas eksperimen diberi perlakuan dengan menggunakan metode NLP dengan teknik VAKOT. Berdasarkan hasil penelitian, penulis mendapatkan uji efek perlakuan dengan nilai 0.2414 yang termasuk ke dalam kriteria efek perlakuan yang sedang. Jadi, perlakuan metode NLP dengan teknik VAKOT dapat memengaruhi teks anekdot dengan kategori sedang.

Kata kunci : pembelajaran menulis teks anekdot, metode NLP dengan teknik VAKOT, metode ekperimen, dan hasil penelitian. 


\section{A. PENDAHULUAN}

Sebagian orang tidak menganggap menulis itu mudah karena menulis membutuhkan sebuah acuan yang dinamakan EyD (Ejaan yang Disempurnakan). EyD merupakan kaidah normatif bagi seseorang dalam menggambarkan lambang-lambang bunyi (kata,frasa, kalimat, dsb) dalam bentuk pemakaian huruf, penulisan kata, serta penggunaan tanda baca. Tentunya sebuah tulisan yang baik itu harus melalui sebuah proses. Seseorang membutuhkan kerja keras, latihan, dan praktik yang berkelanjutan dalam prosesnya. Latihan dan praktik kemampuan menulis dapat dilatih sejak usia dini, mulai dari menulis dan mengenal huruf-huruf secara alfabetis yang kemudian dikembangkan dibangku sekolah dasar, menengah, serta perguruan tinggi menjadi sebuah karangan.

\section{Keterampilan menulis} merupakan kegiatan yang kompleks dalam arti kegiatan menulis sangat pelik, sulit, dan rumit.Bagi seseorang kegiatan menulis sangat kompleks karena pengembangan sebuah ide tulisan harus memiliki kesatuan dan koherensi agar sebuah tulisan menjadi lebih sistematis, logis, dan artistik.Menulis teks anekdot dapat dilakukan seorang siswa ketika mengetahui tentang norma EyD, adanya latihan dan praktik secara kontinu dalam memahami sebuah struktur teks anekdot, serta latihan dan praktik dalam mengembangankan sebuah ide agar sistematis, logis, dan artistik.
Kurangnya minat peserta didik dalam menulis teks anekdot disebabkan oleh kesadaran penggunaan bahasa Indonesia yang kurang baik, belum profesionalnya kinerja pengajar, serta penggunaan metode dan teknik pembelajaran yang kurang tepat. Hal tersebut, berujung pada peserta didik merasa terbebani, kurang antusias, dan kurangnya latihan mengarang.

Dalam mengaktualisasikan pembelajaran menulis yang optimal, pengajar membutukan metode yang diselaraskan dengan teknik yang kreatif dan inovatif.Iskandarwassid dan Sunendar (2008: 66) mengungkapkan teknik merupakan suatu kiat, siasat, atau penemuan yang digunakan untuk menyelesaikan, serta menyempurnakan suatu tujuan langsung.Teknik harus konsisten dengan metode.Oleh karena itu, teknik harus selaras dengan pendekatan. Kemampuan pengajar sangat menentukan dalam memilih teknik mengajar yang akan digunakan agar tujuan pembelajaran dapat tercapai dengan baik. Teknik mempunyai peranan sentral atau strategis karena teknik adalah acuan atau rujukan secara langsung pengaplikasian atau tindakan sebuah metode pembelajaran yang sistematis terarah.

Dewasa ini, NLP (Neuro Lingustic Programming) menjadi jantung bagi berbagai pendekatan komunikasi dan perubahan, serta menjiwai setiap aspek kehidupan manusia.Teknik-teknik dan strategi NLP dipakai untuk keperluan terapi, kesehatan, pendidikan, dan 
sebagainya (Makarao, Ramadhani, 2010: 3).Selanjutnya, Elfiky (2010: 12) mengemukakan teknik-teknik dan strategi NLP dapat diterapakan juga untuk keperluan manajemen dan penjualana.Peran terbesar NLP adalah membantu manusia berkomunikasi lebih baik dengan diri mereka sendiri, mengurangi ketakutan tanpa alasan, mengontrol emosi negatif dan kecemasan. Berdasarkan pendapat Makarao dan Elfiky sangatlah tepat dan penting dalam komunikasi pendidikan didukung dengan teknik-teknik NLP karena NLP menjadi dasar terjalinya hubungan keselarasan komunikasi antara pengajar dan peserta didik.

Selama ini banyak jurnal penelitian mengungkapkan permasalahan terkait tindaktutur seorang pengajar dengan metode NLP.Radislav Millrood (2004) dengan judul "The Role of NLP in Teacher's Classroom

Discourse", mengungkapkan pembelajaran dengan menggunakan NLP selama ini sebagai berikut.

The workshops produced
evidence that teacher
discourse can be considered
as a tool, programming
success or failure in learners
by creating or ruining teacher-
learner congruence through a
set of NLP techniques.

Hasil penelitian tersebut menjelaskan tindaktutur seorang pengajar dianggap sebagai modal penting untuk mencapai keberhasilan dalam pembelajaran dengan menciptakan hubungan antara pengajar dan peserta didik melalui sejumlah teknik NLP.

Jurnal penelitian yang juga mengungkapkan permasalahan terkait dengan pembelajaran menggunakan metode NLP adalah penelitian Tosey Pauldan Mathison Jane (2003) dengan judul "Neurolinguistic Programming and Learning Theory: a response".

I have suggested that Neurolinguistic Programming appears to rest on constructivist theory. This would suggest that learning is personally constructedand negotiated through practical and social interaction in the world.The most powerful constructivist learning theories propose that this involvesa form of direct apprenticeship, in which the expert helps the novice graduallyto gain in confidence, understanding and competence. NeurolinguisticProgramming,

however, is much less concerned with the expert practitioner.l would therefore question how far merely copying, without negotiation, canreally lead to expert performance.

Hasil penelitian tersebut menjelaskan pembelajaran secara personal dibangun melalui sebuah praktik dan interaksi sosial.NLP merupakan strategi untuk menumbuhkan hubungan interaksi sosial antara pengajar dan peserta didik dalam mencapai rasa percaya diri, pemahaman, dan kompetensi. 
Selanjutnya penelitian yang berkaiatan dengan keberhasilan maupun kegagalan sebuah metode NLP yang kemudian dihubungkan dengan teknik VAKOT. Penelitian Peter dan Linda (2002 : 11) dengan judul "Neuro Linguistic Programming The Key To Accelerated Learning".

As suggested in this collage, humans think using a mixture of visual images, auditory images, kinesthetic feelings, awareness of smell and awareness of taste. Sometimes we are successful, sometimes less so. Using NLP we can begin to describe our experience in many useful and interesting ways. (From left to right: hear, see, measure, smell, taste, and touch).

Hasil penelitian tersebut mengungkapkan seseorang disarankan berpikir menggunakan perpanduan antara pengelihatan, pendengaran, perasaan, penciuman, dan pengecap.Berhasil atau tidaknya sebuah metode NLP dapat kita mulai dari menjelaskan sebuah pengalaman pancaindra.Disarankan dapat diartikanseseorang berpikir tidak lepas dari pengalaman pancaindranya. Selanjutnya, keberhasilan sebuah metode NLP, tentunya tidak lepas dari penggalian sebuah pengalaman yang bermanfaat dan menarik dari apa yang dilihat, didengar, dirasa, dicium, dan dikecap. Jadi, metode NLP mempunyai hubungan yangerat dengan teknik VAKOT.

Dalam mengajarkan menulis teks anekdot secara optimal, peserta didik membutuhkan metode yang selaras dengan teknik agar menciptakan pembelajaran menulis yang kreatif dan inovatif. Salah satunya adalah metode NLP dengan teknik VAKOT. Elfiky (2009: 14) mengemukakan definisi ilmiah dari NLP.Neuro mengacu pada sistem syaraf yang menghubungkan pancaindra.Linguistic adalah kemampuan alami berkomunikasi secara verbal dan nonverbal.Programming mengacu pada pola berpikir, perasaan, dan tindakan perilaku yang diharapkan. Dalam memaksimalkan metode NLP ini butuh sebuah teknik yang akan mengoptimalkan pengaplikasiannya, salah satunya adalah teknik VAKOT. Ghannoe (2010 : 49-54) mengungkapkan manusia mempunyai sistem representasi untuk menggambar ulang aktivitas pancaindranya ke dalam sebuah pikiran. Aktivitas pancaindra tidak lepas dari pengembangan teknik VAKOT.Berdasarkan pendapat Elfiky dan Ghannoe, peneliti mengungkapkan bahwa peserta didik dalam menulis teks anekdot dapat menggali pikiran dan imajinasinya melalui pengalaman yang telah dialaminya melalui pancaindra, yaitu dengan teknik VAKOT.Berdasarkan uraian tersebut, peneliti tertarik untuk meneliti pembelajaran menulis teks anekdot.Metode NLP dengan teknik VAKOT sendiri, belum pernah digunakan untuk pembelajaran menulis anekdot. Judul penelitian yang dilakukan adalah "Pembelajaran Menulis Teks Anekdot Melalui Metode NLP dengan Teknik VAKOT 
(Penelitian Eksperimen pada Peserta Didik di Kelas X SMA Negeri 6 Bandung Tahun Ajaran 2013/2014)".

\section{B. KAJIAN TEORI}

Semi (2007:40) menulis merupakan suatu proses kreatif. Artinya, menulis merupakan sebuah keterampilan yang dilakukan melalui tahapan yang harus dikerjakan dengan mengarahkan keterampilan, seni, dan kiat sehingga semuanya berjalan dengan efektif.Selanjutnya, Alwasilah dan Susanna (2007:43) mengungkapkan menulis adalah sebuah kemampuan, kemahiran, dan kepiawaian seseorang dalam menyampaikan gagasannya ke dalam sebuah wacana agar dapat diterima oleh pembaca yang heterogen, baik secara intelektual maupun sosial.Kemampuan, kemahiran, dan kepiawaian dapat diartikan bahwa seorang penulis harus mempunyai kepandaian dalam mengemukakan sebuah gagasan agar tulisannya mampu diterima dan bermanfaat bagi kalangan akademisi maupun nonakademis.

Mulyadi dan Danaira (2013:5) anekdot merupakan lelucon atau humor yang di dalamnya terkandung pelajaran ataupun nasihat.Tujuannya untuk menyindir atau mengingatkan seseorang tentang suatu kebenaran.Mulyadi dan Danaira (2013:35) anekdot merupakan sindiran, mungkin juga berisi kritik, namun dinyatakan dalam bentuk humor.Teks anekdot tidak hanya sebatas menarik, lucu, dan unik saja, tetapi teks anekdot merupakan sejenis cerita pendek yang berisi sindirian atau kritikan yang dinyatakan dalam bentuk humor. Jadi, teks anekdot merupakan sejenis cerita pendek, baik itu cerita nonfiksi maupun fiksi yang menceritakan tentang pengalaman pribadi maupun orang lain yang berisi sindiran atau kritikan yang bersifat humor, serta mengandung rasa kepedulian terhadap sebuah krisis fenomena di masyarakat untuk mengubah sebuah perilaku.

Fungsi anekdot sebagai penunjang dari karangan narasi, sebagai sarana ekspresi dalam mengemukakan sindiran atau kritik untuk mengubah perilaku, serta sebagai sarana hiburan dalam menyampaikan sebuah sindiran atau kritikan yang dinyatakan dalam bentuk humor.Selanjutnya, struktur teks anekdot kerangka utamanya dibagi menjadi tiga komponen, yaitu tokoh, latar, dan alur. Selanjutnya, alur atau cerita teks anekdot ini dikembangkan menjadi lima komponen penting, yaitu abstaksi, orientasi, krisis, reaksi, dan koda.

Dalam mengaktualisasikan pembelajaran menulis yang optimal, pengajar membutukan metode yang diselaraskan dengan teknik yang kreatif dan inovatif. Metode adalah prosedur dapat diartikan sebuah tahapan untuk menyatakan kerangka secara umum dan menyeluruh tentang proses pembelajaran. Selanjutnya, teknik adalah cara khas yang operasional atau tindakan nyata tentang proses pembelajaran yang berpedoman pada metode. Pada pembelajaran bahasa dapat digunakan teknik yang bervariasi. 
Teknik dapat dikembangkan sesuai dengan

kebutuhan

pembelajaran.Pembelajaran bahasa

dapat dilakukan dengan satu atau lebih teknik yang digabungkan sesuai kebutuhan pembelajaran yang dilakukan.Penyajian teknik pembelajaran yang bervariasi tentu dibutuhkan agar pembelajaran bahasa lebih kreatif dan inovatif.

Metode NLP mempunyai teknik yang bervariasi, yaitu teknik meta model, milton model, anchoring, metafora, reframing, submodalitas, perseptual positions, meta program, kesadaran diri, change model, fokus model, generator pembangkit tabiat baru, metode eye-accesing cues (pertunjukan berdasarkan gerak mata), membangun hubungan keselarasan, dan tiga "V" dalam komunikasi.Jenis metode NLP yang digunakan untuk menulis teks anekdot, peneliti berfokus kepada metode sistem representasi yang diaplikasikan melalui teknik VAKOT (Visual, Auditory, Kinesthetic, Olfactory, and Taste).

Elfiky (2010:86) sebagi manusia, kita berinteraksi dengan dunia kita melalui pancaindra kita. Kelima indra kita mengacu pada sistem representasi, penamaan, mengatur, menyimpan, dan menghubungkan kita dengan alat penyaring persepsi kita. Sistem ini terdiri dari lima subsistem: visual, pendengaran, penciuman, pengecap, dan kinestetik. Elfiky mengemukakan kelima pancaindra mengacu pada lima sistem, yaitu representasi, penamaan, mengatur, menyimpan, dan menghubungkan antara manusia dengan pemikirannya.

Ghannoe (2010:49) sistem representasi atau modalitas sensorik merupakan sistem penggambaran ulang aktivitas pancaindra yang kita miliki ke dalam pikiran kita.Sistem representasi inilah yang dalam kehidupan sehari-hari berperan penting dalam membantu kita untuk mengingat, merencanakan, mengagumi, dan memberikan solusi terhadap sesuatu.Sistem representasi ini akan membahas poin-poin penting yang berkaitan dengan pancaindra, otak, dan tindakan atau keputusan. Mulai dari penglihatan, pendengaran, perasaan, senyuman, dan pengecapan, kelima sistem representasi ini dalam NLP dikenal dengan singkatan "VAKOT".Ghannoe mengemukakan kelima pancaindra mempunyai peranan penting dalam kehidupan sehari-hari untuk membatu mengingat, merencanakan, menggagumi, dan memberikan solusi.Pendapat Ghannoe tentang sistem pancaindra tidak hanya menitikberatkan kepada sistem representasi, penamaan, dan menyimpan, tetapi ada sistem mengagumi, serta memberikan solusi.Pendapat Ghannoe tentang sistem representasi pancaindra tidak hanya menitikberatkan pada pemikiran saja, tetapi menghubungkannya dengan tindakan. Jadi, sistem representasi adalah sistem yang menggambarkan aktivitas pancaindra untuk membantu proses mengingat, merencanakan, mengagumi, memberikan solusi, dan 
menghubungkan sebuah interaksi pikiran dengan tindakan.

\section{METODE PENELITIAN}

Pendekatan dalam penelitian ini menggunakan pendekatan kuantitatif dengan menggunakan metode eskperimen.Eksperimen adalah uji coba atau percobaan yang direncanakan atau bersisitem.Metode penelitian eksperimental dapat diartikan sebagai sebuah studi yang objektif, sistematis, dan terkontrol untuk memprediksi dan mengontrol fenomena.Oleh karena itu, tujuan penelitian eksperimental dimaksudkan untuk menguji hubungan kausalitas (Syamsuddin dan Vismaia, 2006: 151).Eksperimen sebuah penelitian yang dikondisikan (artificial condition).Kondisi penelitian diatur oleh peneliti secara penuh.Dengan demikian, metode penelitian eksperimen adalah penelitian untuk mengujicobakan sebuah perlakuan terhadap sebuah objek, serta membandingkanya dengan kelas kontrol (tanpa perlakuan).

Metode eksperimen ini mempunyai validitas yang sangat tinggi.Validitas ini untuk menguji seberapa jauh pengaruh variabel satu atau lebih terhadap variabel lain. Tujuan penelitian eksperimen adalah untuk menyelidiki ada tidaknya hubungan sebab akibat dan berapa besar hubungan sebab akibat tersebut dengan cara memberikan perlakuan-perlakuan tertentu pada beberapa kelompok eksperimen, serta menyediakan kontrol untuk perbandingan.
Sugiyono (2012:73) terdapat empat bentuk desain eksperimen, yaitu sebagai berikut preexperimental, true-experimental, factorial experimental, dan quasiexperimental.Pada penelitian ini peneliti menggunakan desain penelitian true-experimental karena dalam desain ini peneliti dapat mengontrol semua variabel luar yang memengaruhi jalannya eksperimen.Karakteristik utama dari true-experimental adalah sampel yang digunakan untuk ekperimen maupun sebagai kelompok kontrol diambil secara acak/random dari populasi tertentu.Bentuk-bentuk desain penelitian true-experimental, yaitu pretest-posttestcontrol group design.

Tabel 1

\begin{tabular}{|c|c|c|c|}
\hline $\begin{array}{c}\text { Kela } \\
\mathbf{s}\end{array}$ & $\begin{array}{c}\text { Prate } \\
\mathbf{s}\end{array}$ & $\begin{array}{c}\text { Perlakua } \\
\mathbf{n}\end{array}$ & $\begin{array}{c}\text { Pascate } \\
\mathbf{s}\end{array}$ \\
\hline $\mathrm{E}$ & $O_{1}$ & $X_{1}$ & $O_{2}$ \\
\hline $\mathrm{K}$ & $O_{3}$ & & $O_{4}$ \\
\hline
\end{tabular}

Populasi dalam penelitian ini adalah seluruh peserta didik kelas $X$ SMA Negeri 6 Bandung tahun pelajaran 2013/2014 yang berjumlah 10 kelasterdiri atas kelas $\mathrm{X}-1$ sampai kelas $\mathrm{X}-10$. Sepuluh kelas ini terdiri atas, 7 kelas X IPA, dan 3 kelas XIPS. Teknik pengambilan sampel yang digunakan dalam penelitian ini adalah probality sampling dengan model simple random sampling. Simple random sampling dipilih karena pada penelitian ini pengambilan anggota sampel populasi dilakukan secara acak tanpa memperhatikan strata pada populasi sehingga untuk mengambil sampel, 
peneliti mengambil dua kelas tanpa prasangka. Cara ini dipilih karena pada dasarnya setiap kelas memiliki rata-rata karakteristik yang hampir sama. Pemilihanya dengan cara melakukan pengundian dari kelas $X$ IPA-1 samapai IPA-7. Akhirnya didapatkan dua kelas yang dijadikan sampel dalam penelitian ini, yakni kelas X-5 sebagai kelas eksperimen dan kelas $\mathrm{X}-3$ sebagai kelas pembanding.

Instrumen perlakuan, instrumen pengumpulan data, validasi instrumen, dan pengolahan data.Instrumen perlakuan terdiri atas orientasi metode NLP dengan teknik VAKOT, prosedur pelaksanaan perlakuan, dan rencana perencanaan pembelajaran (RPP).Istrumen pengolahan data, yaitu soal tes menulis teks anekdot dan lembar observasi.Validasi instrumen terdiri atas uji validasi intrumen, reliabilitas, daya pembeda, dan uji indeks kesukaran. Selanjuutnya, instrumen akhir adalah pengolahan data dengan menggunakan berbagai perhitungan dan uji terakhir adalah uji efek perlakuan. Rosenthal (1991: 19) mengemukakan uji efek perlakuan dalam sebuah penelitian untuk memverifikasi pengaruh variabel bebas kepada variabel terikat, serta untuk mengetahui seberapa besar pengaruh perlakuan yang diberikan.

Tabel 2

Rumus Efek Perlakuan

$$
r=\sqrt{\frac{t}{t^{z}+a}}
$$

Keterangan : $\mathrm{t}$ : Hasil perhitung independent $t$ test pascates dikurangi prates

df : Jumlah keseluruhan peserta tes

Tabel 3

Kriteria Nilai Efek Perlakuan

\begin{tabular}{|l|l|}
\hline Efek Perlakuan & \multicolumn{1}{|c|}{ Nilai $\mathbf{r}$} \\
\hline Kecil & 0,100 \\
\hline Sedang & 0,243 \\
\hline Besar & 0,371 \\
\hline \multicolumn{2}{|c|}{ (Coolidge, 2000: 151) }
\end{tabular}

\section{HASIL PENELITIAN DAN PEMBAHASAN}

Setelah dilakukan penelitian, diperoleh data tes awal dan tes akhir dari kelas eksperimen.Penelitian ini, terbukti bahwa metode NLP dengan teknik VAKOT terbukti efektif dalam pembelajaran menulis teks anekdot, khususnya di kelas X SMA Negeri 6 Bandung.Berdasarkan perhitungan statistik data berdistribusi normal dan homogen.Data sampel berdistribusi normal membuktikan hasil sampel tersebar dalam kurva yang normal. Terbukti homogen berdasarkan perhitungan statistik dengan tingkat kepercayaan 95\%, membuktikan adanya keseragaman varians antara sampel-sampel dari populasi yang diambil.

Perhitungan statistik mulai dari reliabilitas, uji dua sampel tidak berhubungan, uji normalitas, homogenitas, uji dua sampel berpasangan, dan uji efek perlakuan menunjukan hasil yang baik. Berdasarkan uji reliabilitas pada prates kontrol dan ekperimen mendapatkan nilai, yaitu 9.10 dan 0.94 , sedangakan pada pascates kelas kontrol dan eksperimen 
mendapatkan nilai, yaitu 0.918 dan 0.89. Nilai reliabilitas antarpenimbang adalah 0.89 . Berdasarkan tabel Guilford, maka dapat disimpulkan koefesien reliabilitas antarpenimbang atau objektivitas penilaian prates maupun pascates teks anekdot pada kelas kontrol dan eskperimen ini, termasuk dalam korelasi sangat tinggi dan tinggi. Selanjutnya, uji tidak berhubungan prates kontrol dan eksperimen mendapatkan nilai yaitu, 0.98 , sedangkan pascates kontrol dan ekperimen mendapatkan nilai, yaitu 0.679 , nilai ini membuktikan uji $F$ adalah 0.98 dan 0.679 lebih besar dari 0.05 , maka dapat disimpulkan bahwa kedua varian sama.

\section{Uji normalitas diketahui} bahwa nilai signifikansi prates kelas kontrol dan eksprimen, yaitu, 0,200 dan 0,165, sedangkan nilai signifikansi pascates kelas kontrol dan eksperimen, yaitu 0,200 dan 0,063 lebih besar dari 0,05, maka dapat disimpulkan bahwa populasi prates dan pascates kelas kontrol dan eksperimen berdistribusi normal. Uji homogenitas diketahui bahwa nilai signifikansi prates kelas kontrol dan eksprimen, yaitu, 0,948, sedangkan pascates kelas kontrol dan eksprimen, yaitu, 0,679 lebih dari 0,05 , jadi untuk prates dan pascate kelas kontrol dan eksperimen mempunyai varian sama. Selanjutnya, uji dua sampel berpasangan dapat diketahui bahwa nilai signifikansi prates dan pascate kelas kontrol, yaitu, 0,000, sedangkan prates dan pascate kelas eksperimen, yaitu, 0,000. Karena nilai signifikansi uji dua sampel berpasangan prates dan pascates kelas kontrol dan eksperimen kurang dari 0,05, maka Ho ditolak. Artinya, bahwa ada perbedaan antara ratarata nilai teks anekdot sebelum dan sesudah diberikan metode pembelajaran berbasis masalah dan menggunakan metode NLP dengan teknik belajar VAKOT.

Metode NLP dengan teknik belajar VAKOT sangat efektif dalam pembelajaran menulis teks anekdot pada peserta didik kelas $X$ SMA Negeri 6 Bandung. Hal ini, terbukti berdasarkan uji efek perlakuan dengan nilai 0.2414 yang termasuk ke dalam kriteria efek perlakuan yang sedang. Jadi, perlakuan metode NLP dengan teknik belajar VAKOT dapat memengaruhi teks anekdot dengan kategori sedang.

\section{E. SIMPULAN DAN SARAN}

\section{Simpulan}

Berdasarkan hasil penelitian eksperimen penerapan metode NLP (Pemograman Neurolinguistik) dengan teknik VAKOT (Visual, Audito, Kinestetik, Olfaktori, dan Rasa) dalam pembelajaran menulis teks anekdot pada peserta didik kelas $X$ SMA Negeri 6 Bandung Tahun Ajaran 2013/2014, diperoleh simpulan sebagai berikut.

a. Kemampuan hasil menulis teks anekdot pada prates kelas kontrol maupun kelas eksperimen, peserta didik mengalami hambatan atau kekurangan. Hambatan atau kekurangan peserta didik dalam menulis teks anekdot sangat beragam. Hambatan atau 
kekurangan yang ditemukan dalam menulis teks anekdot, yaitu dari pengembangan isi, struktur, dan kebahasaan. Segi isi, peserta didik sulit mengembangkan dari segi kritikan dan sikap ajakan untuk mengubah perilaku. Segi struktur, peserta didik sulit dalam mengembangkan reaksi dan koda yang optimal. Aspek kebahasaan, peserta didik sangat sulit dalam ejaan, tanda baca, kalimat, dan konjungsi. Jadi, peserta didik dalam menulis teks anekdot pada prates masih belum optimal karena masih ditemukan kekurangan dalam mengembangan segi isi dan kebahasaan.

b. Kemampuan hasil menulis teks anekdot pada pascates kelas kontrol maupun kelas eskperimen mengalami sedikit perkembangan. Kelas kontrol dalam pengembangan teks anekdot dari segi isi hanya kurang optimal dalam pengembangan kritikan, kemudian pada segi aspek kebahasaan masih terdapat beberapa kesalahan dari tanda baca dan kalimat saja. Selanjutnya, pascates pada kelas eksperimen peserta didik dalam pengembangan isi mulai menambahkan kritikan yang optimal. Kritikan yang optimalah yang dapat membangun sebuah ajakan untuk merubah perilaku ke arah yang lebih baik. Aspek kebahasaan, peserta didik mulai menampakan perbaikan dari segi ejaan, tanda baca, dan konjungsi, tetapi peserta didik masih ada kesulitan dalam mengembangkan kalimat. Jadi, peserta didik dalam menulis teks anekdot pada pascates kelas kontrol dan eksperimen sudah mengalami peningkatan.

c. Hasil menunjukan nilai pascates kelas kontrol yang menggunakan metode pembelajaran masalah lebih rendah dibandingkan kelas eksperimen yang menggunakan metode NLP dengan teknik VAKOT . Metode NLP dengan teknik VAKOT terbukti efektif dalam pembelajaran menulis teks anekdot pada peserta didik kelas $X$ SMA Negeri 6 Bandung. Hal ini, terbukti dengan nilai 0.2414 yang termasuk ke dalam kriteria efek perlakuan yang sedang. Jadi, perlakuan metode NLP dengan teknik VAKOT dapat memengaruhi teks anekdot dengan kategori sedang.

\section{Saran}

Berdasarkan hasil penelitian dan simpulan di SMA Negeri 6 Bandung yang diperoleh, maka diajukan beberapa saran sebagai berikut.

a. Berdasarkan hasil penelitian, metode NLP dengan teknik belajar VAKOT terbukti efektif dalam meningkatkan kemampuan peserta didik dalam menulis teks anekdot. Oleh karena itu, peneliti memberikan saran agar metode NLP dengan teknik belajar VAKOT dapat diimplementasi sebagai alternatif pengembangan teknik baru pada Kurikulum 2013 Bahasa Indonesia. 
b. Metode NLP dengan teknik belajar VAKOT dapat menciptakan atau membangun strategi komunikasi yang lebih baik dan unggul antara para pengajar dan peserta didik. Jadi, sangatlah disarankan teknik VAKOT tidak hanya diterapkan dalam ketermapilan menulis teks anekdot saja, tetapi dalam keterampilan menulis lainya seperti menulis teks eksposisi, teks prosedur kompleks, teks observasi, dan teks negosiasi.

c. Metode NLP dengan teknik belajar VAKOT disarankan dikolaborasikan dengan media agar suasana pembelajaran lebih antusias, efektif, dan kreatif.

d. Metode NLP mempunyai teknik yang bervariasi, maka disarankan tidak hanya menggunakan teknik VAKOT saja, tetapi menggunakan lain seperti teknik meta model, milton model, anchoring, metafora, reframing, submodalitas, perseptual positions, meta program, kesadaran diri, change model, fokus model, generator pembangkit tabiat baru, metode eye-accesing cues (pertunjukan berdasarkan gerak mata), membangun hubungan keselarasan, dan tiga " $\mathrm{V}$ " dalam komunikasi.

\section{DAFTAR PUSTAKA}

Akhadiah, S. dkk. (2003). Pembinaan kemampuan menulis bahasa Indonesia. Jakarta: Erlangga.

Alwasilah, A.C. dan Susanna, S. (2007). Pokoknya menulis:
Cara baru menulis dengan metode kolaborasi. Bandung: Kiblat Buku Utama.

Arikunto, S. (2010). Prosedur penelitian suatu pendekatan praktik. Jakarta: Rineka Cipta.

Coolidge, F.L. (2000). Statistic "A gantle intrudaction". London: Cromwell Press.

Danandjaja, J. (1997). Folklor Indonesia ilmu gosip, dongeng, dan lain- lain. Jakarta: PT Pustaka Utama Grafiti.

Djuherli dan Suherli. (2005). Panduan membuat karya tulis. Bandug. Yrama Widya.

Elfiky, I. (2010). Terapi komunikasi efektif dengan metode praktis neuro-linguistic programming (NLP). Jakarta: Hikmah.

Finoza, L. (2007). Komposisi bahasa Indonesia. Jakarta: Diksi Insan Mulia.

Ghannoe.(2010). Buku pintar NLP. Yogyakarta: Flash Books.

Hendarto, P. (1990). Filsafat humor. Jakarta: Karya Megah.

Hendratna, G. (2011). Jalan meraih sukses dengan metode NLP. Bekasi: Segoro IImu.

Husen, I.S. (2001). Meretas ranah bahasa, semiotika, dan budaya. Jogjakarta: Yayasan Bentang Budaya.

Iskandarwassid dan Sunendar.(2008). Strategi pembelajaran bahasa. Bandung: Remaja Rosdakarya. 
Keraf, G. (2010). Argumentasi dan narasi. Jakarta: Gramedia Pustaka Utama.

Kosasih, E. (2008). Ketatabahasaan dan kesussastraan. Bandung: Yrama Widya.

Lum, M. (2009). NLP secret. Mitra Media.

Makaraho, R. N. (2010). NLP komunikasi konseling. Bandung: Alfabeta.

Maryanto, dkk. (2013). Bahasa Indonesia ekspresi diri dan akademik. Jakarta: Politeknik Negeri Media Kreatif.

Millrod, R. (2004). The role of NLP in teacher's classroom discourse. [Online]. Tersedia di:

http://203.72.145.166/ELT/file s/58-1-4.pdf.htm [Diakses 20 Desember 2013].

Mulyadi,Y. dan Danaira, F. (2013). Bahasa Indonesia untuk SMA-MAISMK kelas $X$. Bandung: YramaWidya.

Natalia, M. M. dan Dewi, K. I. (2008). Aplikasi NLP dalam pembelajaran. Bandung: Tinta Emas Publishing.

Nurgyantoro, B. (2001). Penilaian pembelajaran bahasa berbasis kompetensi.

Yogyakarta: BPFEYogyakarta.

Nurhayatin, T. (2009). Penilaian pembelajaran bahasa dan sastra Indonesia berbasis kelas. Bandung: Prisma Press.

Peter dan Linda. (2002). Neurolinguistic programming, the key to accelerated learning.
[Online]. Tersedia di: http://www.turtletrader.com/nl p-introduction.pdf.htm [Diakses 14 Juni 2014].

Priyono, H. (2010). Mind writing. Yogyakarta: Leutika.

Priyatno, D. (2010). Paham analisis statistik data dengan SPSS. Yogyakarta: Mediakom.

Rizkia, F.M. (2013). Efektivitas NLP dalam menulis cerita pendek di kelas X SMA Pasundan 7 Bandung. [Online]. Tersedia di:

http://repository.upi.edu/2849/ 2/S/IND/0906400/Abstaract.p df.htm [Diakses 21 Desember 2013].

Rosenthal, R. (1991). Meta-analytic procedures for social research. California: Sage Publication Inc.

Semi, A.M. (2007). Dasar-dasar keterampilan menulis. Bandung: Angkasa.

Setiawan, A. (1990). Teori humor. Jakarta: Majalah Astaga

Subana, M. dan Sudrajat.(2005). Statistik pendidikan. Bandung: Pustaka Setia.

Sugiono. (2013). Sistem representasi manusia. [Online]. Tersedia di:

http://nlpcepat.com/sistem-representasi-manusia.htm [Diakses14 Juni 2014].

Sugiyono. (2012). Metode penelitian kombinasi (mixed methods). Bandung: Alfabeta.

Suhendar, E. M. dan Supinah, P. (1997). Mata kuliah dasar umum. Bandung: Pionir Jaya. 
Suherman, E. dkk. (2003). Strategi pembelajaran matematika kontemporer. Bandung :JicaImstep Project.

Suparno dan Yunus, M. (2008). Keterampilan dasar menulis. Jakarta: Universitas Terbuka.

Syamsuddin, A. R. dan Vismaia, S. D. (2006). Metode penelitian pendidikan bahasa. Bandung: Remaja Rosdakarya.

Tarigan, H. G. (2008). Menulis sebagai suatu keterampilan berbahasa. Bandung: Angkasa.

Tjandra, I. A. (2011). Penerapan NLP dalam menulis karangan eksposisi di kelas $X$ SMK 3 Bandung. Skripsi FPBS UPI: Tidak diterbitkan.

To, K. (2003). Mengenal Analisis Tes (Edisi ke-2). Bandung: Universitas Pendidikan Indonesia

Tosey, P. dan Jane, M. (2003). Neurolinguistic programming and learning theory a response. [Online]. Tersedia di: http://epubs.surrey.ac.uk/118 6/1/fulltext.pdf.htm [Diakses 20 Desember 2013].

Totok. (2013). Buku saku NLP. Yogyakarta: Pohon Cahaya.

Wachidah, S. (2004). Pembelajaran teks anekdot. Jakarta: Departemen Penddidikan Nasional Direktorat Jenderal Pendidikan Dasar dan Menengah Direktorat Pendidikan Lanjut Pertama.

Widjaja, A.W. (1983). Komunikasi dan hubungan masyarakat. Jakarta: Bumi Aksara.
Wijana, I. (1995). Pemanfaatan teks humor dalam pegajaran aspek-aspek kebahasaan. Jurnal bahasa studi dan pengajaran: Bahasa Humor, 1 (2), hlm. 23-30.

Wikanengsih. (2009). Menerapkan neuro linguistic programming (NLP) dalam pembelajaran bahasa. Bandung: Jurusan Pendidikan Bahasa dan Sastra Indonesia FPBS UPI.

Yudiantara, P. (2012). Strategi belajar neuro-linguistic programming (NLP):Beberapa teknik belajar dengan pendekatan neuro-linguistic programming (NLP) untuk hasil belajar yang luar biasa. [Online]. Tersedia di: http://yudiantara.wordpress.c om/2012/08/07/strategibelajar-neuro-linguisticprogramming-nlp-beberapateknik-belajar-denganpendekatan-neuro-linguisticprogramming-nlp-untuk-hasilbelajar-yang-luar-biasa.htm 